\title{
Perception and attitude of mothers toward family planning in Southern Nigeria
}

\author{
EMMANUEL COLUMBA INYANG-ETOH ${ }^{A, D-G}$, MATTHIAS GABRIEL ABAH ${ }^{\mathrm{A}, \mathrm{B}-\mathrm{D}}$ \\ Department of Obstetrics and Gynecology, University of Uyo, Nigeria
}

A - Study Design, B - Data Collection, C - Statistical Analysis, D - Data Interpretation, E - Manuscript Preparation, F - Literature Search, G - Funds Collection

\begin{abstract}
Summary Background. The prevailing low utilization of modern contraceptives for family planning in developing countries in spite of an almost universal level of awareness by the populace is a cause for concern by relevant stakeholders.

Objectives. The aim of this study was to determine the feeling and attitude of women toward family planning and the reasons for such attitude.

Material and methods. A 7-item structured, pre-coded questionnaire was used to sample respondents' feelings and attitude toward family planning.

Results. All the respondents were aware of family planning, and 412 (90.9\%) of them believed in the practice. The majority 269 (59.4\%) of the respondents preferred to allow 24 months between their last delivery and the next pregnancy. 306 (74.3\%) respondents believed in the use of modern contraceptives for family planning and preferred: the male condom - $160(52.3 \%)$, intrauterine contraceptive device (IUCD) - $27(8.8 \%)$, and hormonal contraceptives - $119(38.9 \%)$. Those who did not believe in modern contraception preferred abstinence $-12(11.3 \%)$, the withdrawal technique $-75,(70.8 \%)$ and the rhythm method $-19(17.9 \%)$. The major reasons why some respondents would not use modern contraceptives for child spacing were the feeling that it is not natural $-39(36.6 \%)$, it could fail $-13(12.2 \%)$, fear of side effects $-41(39.0 \%)$, and the fear that it could cause infertility $-13(12.2 \%)$.

Conclusions. The willingness to utilize modern contraceptives for family planning in Nigeria remains relatively low despite a universal level of awareness about the practice. This is due to misconceptions about modern contraception.

Key words: awareness, attitude, modern contraceptives, utilization, reasons, family planning.
\end{abstract}

Inyang-Etoh EC, Abah MG. Perception and attitude of mothers toward family planning in Southern Nigeria Fam Med Prim Care Rev 2017; 19(2): 134-138, doi: https://doi.org/10.5114/fmpcr.2017.67867.

\section{Background}

Family planning has been recognized as a panacea for healthy motherhood with a multiplier favorable socioeconomic impact on the family, society, the nation and the world at large. A family is said to be planned when a couple uses modern contraceptives and other methods of birth control to regulate the number, timing and spacing of pregnancies [1-3]. Family planning allows the couple, particularly the woman, to have control over her fertility without the need for any adjustments in her social and sexual life.

The utilization of different measures to regulate human reproduction is not a completely modern phenomenon, as throughout history, humans have used primitive and traditional methods, like periodic abstinence, prolonged lactation, extra-vaginal intercourse, the withdrawal technique, barrier methods and even self-induced abortions in an attempt to regulate their fertility with variable levels of success $[4,5]$. Some of such measures were not without their demerits and danger to maternal health. Expansion in scientific knowledge and technological development have, however, revolutionized these efforts in modern times, resulting in contraceptive methods that are safe and highly effective, promoting maternal health and infant survival $[6,7]$.

The fertility rate globally has decreased considerably due to an escalation in the use of modern contraceptives, especially in developing countries in the last 3 decades $[8,9]$. Generally, in the 1960s, only about $9 \%$ of married women in developing countries practiced any form of contraception, as opposed to $62 \%$ at present [10]. As a result of increased contraceptive use, the unmet need for family planning has also declined from 15\% to $12 \%$ worldwide, but remains above $25 \%$ in most African countries [11]. In Nigeria, for instance, a recent national demographic health survey revealed that $85 \%$ of women are aware of contraception, but only $15 \%$ of currently married women use a method of contraception, leaving an unmet need for family planning of $16 \%$ in the country [12].

Several studies in Sub-Saharan Africa have adduced reasons for the low prevalence of contraceptive use by women in the sub-continent despite the almost universal level of awareness. Some of the factors identified include inadequate knowledge, as well as misconceptions and myths about the use of modern contraceptives [7, 13]. Some of the myths about contraception in Africa are the belief that use of contraceptives is associated with health problems, that contraceptives have serious side effects and that contraceptives could cause infertility [7, 13, 14].

Failure to utilize contraceptives invariably results in unintended pregnancies and short birth intervals, which pose serious health risks to mothers and their infants [1]. Notably, some unintended pregnancies result in unsafe abortions, which carry significant risk that could result in maternal mortality [1, 12]. The national demographic health survey in Nigeria has revealed that birth intervals of less than $\mathbf{2 4}$ months are often associated with poor health outcomes, especially for the baby, who is at increased risk of sickness and death during infancy [12].

\section{Objectives}

There has been an observation that the majority of women accessing maternity care in the University of Uyo Teaching Hospital, Nigeria, when counseled on the need for family planning 
during their postnatal visits, often decline to utilize modern contraceptives for child spacing. This study, therefore, sought to determine the perception and attitude of Nigerian women toward the use of modern contraceptives for family planning.

\section{Material and methods}

\section{Study design and study area}

A cross-sectional, questionnaire-based descriptive study of mothers who attended antenatal care during a two-month period from $1^{\text {st }}$ October to $30^{\text {th }}$ November 2015 in the Maternity Unit of the University of Uyo Teaching Hospital, Uyo, Nigeria, was conducted.

The University of Uyo Teaching Hospital is a specialist hospital, which serves as a referral center for Akwa Ibom State and its environs. It is located in the south-south geopolitical zone of $\mathrm{Ni}$ geria. Nigeria is divided into six geopolitical zones namely, south-south, south-east, south-west, north-central, north-east and north-west. Akwa Ibom State has a population of 3.9 million people according to the Nigerian census conducted in 2006 and is projected to have 5.1 million people by 2015 [12]. The people of the state are predominantly government employed civil servants, public servants working in corporate organizations and other persons indulging in peasant farming, petty trading, fishing, as well as small and medium scale businesses [12].

\section{Data collection and analysis}

The Ethical Committee of the University of Uyo Teaching Hospital had granted approval before commencement of the study. Selected resident doctors in the department were trained to serve as research assistants and to administer the questionnaires to women attending antenatal care in the center during the study period. The mothers were counseled on the purpose of the study and informed that participation in the study was voluntary. The freedom of the women to withdraw from the study at any time should they desire to do so was emphasized. Women who declined to participate in the study, those who were found to be emotionally unstable and anyone who had a mental illness were excluded from the study.

The questionnaire, which was structured and partly pre-coded, had been pretested in a general hospital in Uyo to improve the validity and reliability of the questions. The questionnaires were administered by research assistants to a cross section of women attending antenatal care on every clinic day for the period of the study for self-completion. Respondents who were not literate were assisted through interpretation to complete the questionnaires, and those who needed explanations were attended by the research assistants. Questions were set to obtain the demographic and obstetric parameters of the respondents, awareness about family planning, individual perception about family planning, preferred delivery-pregnancy interval, perception about use of modern contraceptives in child spacing, preferred method of modern contraceptives for family planning for those who believed in it, as well as other methods preferred by respondents who did not believe in modern methods. Four closed-ended questions and three open-ended questions that focused on awareness of contraception, perception and attitude of the respondents toward family planning were asked. The respondents were also asked about their preferred inter-pregnancy interval and reasons for their contraceptive preferences.

Data generated from the study was coded and entered into the software of the Statistical Package for Social Sciences (SPSS), Version 17 Inc. Chicago, Illinois, USA. All the variables were normally distributed, as was confirmed by the Shapiro-Wilk normality test. Descriptive statistics were performed for continuous variables, and deductions were made using descriptive and inferential statistics.

\section{Results}

A total of 453 eligible women attending antenatal care in the Maternity Unit of the University of Uyo Teaching Hospital during the study period participated in the study. The mean age of respondents was $29.07 \pm 4.70$ years, with a mean weight of $78.61 \pm 16.01 \mathrm{~kg}$. Table 1 shows the demographic and obstetric parameters of the women in the study population.

Table 1. Demographic and obstetric characteristics of women in the study population

\begin{tabular}{|l|l|l|}
\hline $\begin{array}{l}\text { Demographic and obstetric } \\
\text { characteristics }\end{array}$ & $n$ & $\%$ \\
\hline
\end{tabular}

\begin{tabular}{|c|c|c|}
\hline \multicolumn{3}{|l|}{ Marital status } \\
\hline Married & 428 & 94.5 \\
\hline Engaged & 14 & 3.1 \\
\hline Single & 9 & 2.0 \\
\hline Widowed/divorced & 2 & 0.4 \\
\hline \multicolumn{3}{|l|}{ Religion } \\
\hline Christianity & 448 & 98.9 \\
\hline Islam & 5 & 1.1 \\
\hline \multicolumn{3}{|l|}{ Educational level } \\
\hline No formal education & 3 & 0.7 \\
\hline Primary secondary & 21 & 4.6 \\
\hline Secondary & 140 & 30.9 \\
\hline Post-secondary & 289 & 63.8 \\
\hline \multicolumn{3}{|l|}{ Occupation } \\
\hline Unemployed & 141 & 31.1 \\
\hline Unskilled & 114 & 25.2 \\
\hline Semiskilled & 56 & 12.4 \\
\hline Skilled/Technical & 127 & 28.0 \\
\hline Professional & 15 & 3.3 \\
\hline \multicolumn{3}{|l|}{ Booking status } \\
\hline Booked & 404 & 89.2 \\
\hline Un-booked & 38 & 8.4 \\
\hline Referred & 11 & 2.4 \\
\hline Total & 453 & 100.0 \\
\hline
\end{tabular}

Most of the women were married -428 (94.5\%), Christians $-448(98.9 \%)$, and had booked $-404(89.2 \%)$, receiving antenatal care in the center. The majority - $289(63.8 \%)$, had attained a post-secondary level of education and 141 (31.1\%) of them were unemployed.

Perception and attitude of respondents toward family planning is shown in Table 2. All the respondents were aware of family planning, and most $-412(90.9 \%)$, of the respondents believed in family planning. The majority - 269 (59.4\%), of the respondents preferred to allow 24 months between their last delivery and the next pregnancy, while $8(1.8 \%)$ opted for a delivery-pregnancy interval of 6 months or less. 306 (74.3\%) respondents believed in the use of modern contraceptives for family planning, while $106(25.7 \%)$ did not. Respondents that believed in modern contraception preferred: the male condom - 160 (52.3\%), intrauterine contraceptive device (IUCD) - 27 (8.8\%), and hormonal contraception - 119 (38.9\%). Those who did not believe in modern contraception preferred abstinence - $12(11.3 \%)$, the withdrawal technique - $75(70.8 \%)$, and the rhythm method - 19 (17.9\%). The major reasons why some respondents would not use modern contraception for child spacing were the feeling that it is not natural $-39(36.6 \%)$, it could fail $-13(12.2 \%)$, the fear of side effects $-41(39.0 \%)$, and the fear that it could cause infertility $-13(12.2 \%)$. 


\begin{tabular}{|c|c|c|}
\hline & $n$ & $\%$ \\
\hline \multicolumn{3}{|l|}{ Are you aware of family planning? } \\
\hline Yes & 453 & 100.0 \\
\hline No & 0 & 0.0 \\
\hline \multicolumn{3}{|l|}{ Do you believe in family planning? } \\
\hline Yes & 412 & 90.9 \\
\hline No & 41 & 9.1 \\
\hline \multicolumn{3}{|c|}{ Delivery-pregnancy interval preferred } \\
\hline$\leq 6$ months & 8 & 1.8 \\
\hline 12 months & 161 & 35.5 \\
\hline 24 months & 269 & 59.4 \\
\hline 36 months & 15 & 3.3 \\
\hline Total & 453 & 100.0 \\
\hline \multicolumn{3}{|c|}{ Do you believe in modern contraception for family planning? } \\
\hline Yes & 306 & 74.3 \\
\hline No & 106 & 25.7 \\
\hline Total & 412 & 100.0 \\
\hline \multicolumn{3}{|l|}{ If yes, what method do you prefer? } \\
\hline Male condom & 106 & 52.3 \\
\hline Intrauterine contraceptive device & 27 & 8.8 \\
\hline Hormonal contraceptives & 119 & 38.9 \\
\hline Total & 306 & 100.0 \\
\hline \multicolumn{3}{|c|}{ If no, what other methods do you prefer? } \\
\hline Abstinence & 12 & 11.3 \\
\hline Rhythm method & 19 & 17.9 \\
\hline Withdrawal technique & 75 & 70.8 \\
\hline \multicolumn{3}{|c|}{$\begin{array}{l}\text { What are your reasons for not believing in modern contracep- } \\
\text { tion }\end{array}$} \\
\hline It's not natural & 39 & 36.6 \\
\hline It could fail & 13 & 12.2 \\
\hline Fear of side effects & 41 & 39.0 \\
\hline It can cause infertility & 13 & 12.2 \\
\hline Total & 106 & 100.0 \\
\hline
\end{tabular}

tural differences, obstetric populations in northern Nigeria usually largely comprise younger Muslim women with lower levels of formal education [12].

All the respondents were aware of contraception, with most 412 (90.9\%) believing in the practice, in confirmation with findings from earlier studies in Nigeria, which has been captured in the current national demographic health survey [12]. This result is also in agreement with findings obtained from studies from other geopolitical zones of Nigeria, Uganda and Pakistan $[7,14,17,18]$. Knowledge and awareness of available health care services or risky health behavior among married women could be influenced by education, wealth and media exposure, as demonstrated by a study on awareness and behavior regarding sexually transmitted diseases (STDs) and HIV/AIDS in Bangladesh [19]. It is, however, noteworthy that awareness about contraception does not translate into willingness to practice the same; besides, general awareness about contraception could embellish inadequate knowledge that might be laced with misinformation and misconceptions $[14,17]$.

It was assuring to find that the majority - 269 (59.4\%), of the respondents opted to delay their delivery-pregnancy interval by 24 months, which provides an appropriate birth interval. This finding is set against the backdrop that several studies have identified a birth interval of 24 months or longer to be associated with optimal maternal health and child survival $[1,12,20]$. A vast majority - 306 (74.3\%), of the respondents believed in the use of modern contraception to space their pregnancies, with 160 (52.3\%) opting for the male condom, 27 (8.8\%) opting for an intrauterine contraceptive device (IUCD), while 119 $(38.9 \%)$ opted for hormonal methods. This finding is comparable to results obtained from a similar study in India, where $36.4 \%$ of respondents opted for the male condom, $5.5 \%$ opted for IUCD and, in addition, $8.3 \%$ opted for traditional methods [21]. Similarly, the study in Cross River State, Nigeria, showed a comparable proportion (46.6\%) of respondents opting for the male condom and $10.7 \%$ opting for IUCD, although a much larger proportion (61.2\%) of respondents opted for hormonal methods [16].

In this study, respondents who opted for traditional methods like the withdrawal technique were $75(70.8 \%)$, which was much higher than $20.9 \%$ of the respondents from the Cross River State study [16]. In contrast, while 19 (17.9\%) of the respondents in this study opted for the rhythm method, a higher proportion of women (33.5\%) opted for the same method in the Cross River State study, and in addition, no respondent in that series chose abstinence as a method of family planning [16]. Notwithstanding, use of the male condom and abstinence were preferred by the majority of respondents in a study conducted in Ibadan, southwest Nigeria [17]. In contrast, the majority of women from developed countries of Europe and America prefer to utilize one of the more effective modern contraceptive methods [15].

Major impediments to the use of modern methods of contraception among the respondents were the perception that they were not natural $-39(36.6 \%)$, they could fail - $13(12.2 \%)$, fear of side effects $-41(39.0 \%)$, and the feeling that they could cause infertility - $13(12.2 \%)$, which was similar to revelations from other studies in Africa [13, 22, 23]. Fear of side effects might be the reason relatively few women in this study population opted for hormonal methods. These results, however, contrasted with findings from a study in Uganda, where fear of side effects accounted for why a vast majority (88.2\%) of respondents in that series would not use a modern contraceptive [18]. Interestingly, respondents in the study in Ibadan, southwest Nigeria, would not use modern contraceptives because of concern about certain side effects like stomach ache, menstrual abnormality and loss of fertility [17]. Respondents from a study in Pakistan, on the other hand, would not use modern contraceptives because of concern about negative perception by their in-laws, contrasting religious beliefs and lack of access to quality 
services in their areas [14]. Notwithstanding, women from developed Western countries are more concerned about the efficacy of a given method, nondaily usage or reversibility, and over half $(58 \%)$ of the respondents in that series did not mind certain side effects, like changes in their menstrual pattern, in a global online survey of hormonal contraception users [15, 24]. These contrasting findings are a reflection of differences in the level of awareness and preferences of women regarding contraception in developing and developed countries of the world.

\section{Study limitations}

The study population of this research was drawn through a non-probability convenient sampling technique, so the results may not be a true representation of the entire Nigerian obstetric population. The tool for data collection was a questionnaire, which was structured and in part pre-coded; the array of options provided may not have been exhaustive enough to capture all possible options.

\section{Conclusions}

In conclusion, all the respondents in the study population were aware of family planning, and most of them believed in the practice. Even though the majority of respondents made the right choice and opted to space their pregnancies for 24 months, a modest $74.3 \%$ believed in using modern contraceptives to space their pregnancies, with only $38.9 \%$ opting for hormonal methods. Major impediments to the use of modern contraceptives among respondents were the feeling that it was not natural, it could fail, fear of side effects and concern that it could cause infertility. The need for intensification of public enlightenment on the essence of modern contraception for family planning in developing countries has become imperative.

Acknowledgments. We are grateful to the antenatal clinic nurses and the resident doctors in the department who assisted in the collection of data for this research.

Source of funding: This work was funded by the author's resources. Conflict of interest: The author declares no conflict of interests.

\section{References}

1. Dibaba Y. Child spacing and fertility planning behavior among women in Mana district, Jimma zone, South-west Ethiopia. Ethiop J Health Sci 2010; 20(2): 83-90.

2. Tsui AO, McDonald-Mosley R, Burke AE. Family planning and the burden of unintended pregnancies. Epidemiol Rev 2015; 32(1): 152-174.

3. Olaitan OL. Factors influencing the choice of family planning among couples in southwest Nigeria. Int J Med Med Sci 2011; 7(3): 227-232.

4. Potts M, Campbell M. History of contraception. Glob Libr Women's Med 2009; 3-5, doi: 10.3843/GLOWM.10376.

5. Campbell KL, Wood JW. Fertility in traditional societies. In: Diggory P, Potts M, Teper S. eds. National Fertility. London: Macmillan Press; 1988: 39-69.

6. Mansour D, Inki P, Gemzell-Danielsson K. Efficacy of contraception methods: a review of the literature. Eur J Contracept Reprod Health Care 2010; 5(1): 4-16

7. Mafiayai MJ, Emmanuel AG, Solomon MB, et al. Perception and practice of family planning among rural women in North central Nigeria. Continental J Medical Research 2014; 1(8): 14-19.

8. United Nations Population Fund (UNPF). State of the world population 2007: unleashing the potential of urban growth. New York; 2007.

9. Bongaarts J. Trends in unwanted childbearing in the developing world. Stud Fam Plann 1997; 28: 267-277, doi: 10.2307/ 2137858pmid:9431648.

10. Creanga AA, Gillespie D, Karklins $S$, et al. Low use of contraception among poor women in Africa: an equity issue. Bull World Health Organ 2011; 89: 258-266, doi: 10.2471/BLT.10.083329.

11. Alkema L, Kantorova V, Menozzi C, et al. National, regional and global rates and trends in contraceptive prevalence and unmet need for family planning between 1990 and 2015: a systematic and comprehensive analysis. Lancet 2013; 381(9878): 1642-1652

12. National Population Commission (NPC) Nigeria. National Demographic and Health Survey (NDHS). Final report on fertility rates, contraceptive use and birth interval among Nigerians. Abuja, Nigeria: NPC, NDHS; 2015.

13. Gueye A, Speizer IS, Okigbo CC. Belief in family planning myths at the individual and community levels and modern contraceptive use in urban Africa. Int Perspect Sex Reprod Health 2015; 4(14): 191-199.

14. Mustafa G, Azmat SK, Hameed W, et al. Family planning knowledge, attitude and practices among married men and women in rural areas of Pakistan: findings from a qualitative need assessment study. Int J Reprod Med 2015; 2015: 1-8, doi: doi.org/10.1155/2015/190520.

15. Hooper DJ. Attitudes, awareness, compliance and preferences among hormonal contraception users: a global, cross-sectional, selfadministered, online survey. Clin Drug Investig 2010; 30(11): 749-763, doi: 10.2165/11538900-000000000-00000.

16. Undelikwo VA, Osonwa OK, Ushie MA, et al. Family planning behavior and decision-making among couples in Cross River State, Nigeria. International Journal of Learning and Development 2013; 1(3): 100-120.

17. Taiwo PAJ. Knowledge and perception about family planning among women in selected rural communities of Ibadan. African Journal for the Psychological Study of Social Issues 2012; 2(15): 271-291.

18. Orach CG, Otim G, Aporomon JF, et al. Perceptions, attitude and use of family planning services in post conflict Gulu district, northern Uganda. Bio Med Central 2015; 9(1): 24-34, doi: 10.1186/s13031-015-0050-9.

19. Rana J. Social determinants of awareness and behavior regarding STDs and HIV/AIDS among ever married women in Bangladesh. Fam Med Prim Care Rev 2016; 18(4): 460-469, doi: https://doi.org/10.5114/fmpcr.2016.63702.

20. El-hamid AAA, Gaafar HM. Adverse effects of inter-pregnancy interval on maternal health among pregnant women attending delivery at El-Manial University hospital- Cairo University. Med J Cairo Univ 2011; 2(79): 31-41.

21. Bajwa SK, Bajwa SJS, Ghai GK, et al. Knowledge, attitudes, beliefs and perception of the north Indian population toward adoption of contraceptive practices. Asia Pac J Public Health 2012; 6(24): 1002-1012, doi: 10.1177/1010539511411473.

22. Orji EO, Onwudiegwu U. Prevalence and determinants of contraceptive practice in a defined Nigerian population. J Obstet Gynecol 2002; 22(5): 540-543.

23. Otoido VO, Oronsaye FE. Why Nigerian adolescents seek abortion rather than contraception: evidence from focus group discussions. International Family Planning Perspectives 2001; 27(2): 77-81.

24. Mansour D. International survey to assess women's attitudes regarding choice of daily versus nondaily female hormonal contraception. Int J Womens Health 2014; 3: 367-375, doi: 10.2147/IJWH.S59059. 
Tables: 2

Figures: 0

References: 24

Received: 04.12.2016

Revised: 14.02.2017

Accepted: 02.03.2017

Address for correspondence:

Emmanuel C. Inyang-Etoh, MD, PhD

P.O. Box 200, Ikot Ekpene

Akwa Ibom State

Nigeria

Tel.: 2348033452822, 2347034038318

E-mail: emmacol2000@yahoo.com 